\title{
Identifying Mobile Indicators that Reflect the Functioning of Biological Systems Depending on the Environmental Factors"
}

\author{
Svetlana Failievna Sukhanova \\ Studies of Problems in the Farming Sector, \\ an R\&D Institute, \\ Kurgan State Agricultural Academy \\ named after T.S. Maltsev \\ Kurgan, Russia \\ nauka007@mail.ru
}

\author{
Ruslan Musarbievich Bischokov \\ Department of Informatics and Modeling \\ of Economic Processes, \\ Kabardino- Balkarian State Agricultural University \\ named after V.M. Kokov \\ Nalchik, Russia \\ rusbis@mail.ru
}

\begin{abstract}
Mobile indicators have been established (productive indicators, biological indicators and natural resistance) that show a high degree of susceptibility to influence of various external factors, including feeding ones. A large influence quantity of the feeding factors onto poultry productivity was established, including that onto meat productivity indicators. The identified mobile indicators , such as blood biochemistry levels and leukocyte count may not be used for evaluation of the degree of influence from the feed-linked factors, as the influence quantity varied significantly, depending on both the type of the feed and the indicators being evaluated.
\end{abstract}

Keywords-productivity indicators, biological indicators, environmental factors, biological systems, influence quantity

\section{INTRODUCTION}

Study of factors influencing a living organism shall be conducted with considerations for a detailed analysis of system elements and their interactions with the environment. This model does not allow for an analytical study, but its parameters have a clear physical and biological meaning, and if the components of the system are well-studied, it may produce a quality prediction of response to various environmental factors [1-6].

Each factor used to improve animal productivity has its influence quantity; it influences the organism and causes changes in it. A mandatory stage in evaluation of influence quantity over certain indicators is a variance analysis (ANOVA) that allows estimating what influence one or several controlled factors have over a resulting variable value of the research [7 - 10].

The objective of this research was to determine the influence quantity of environmental (feed-related) factors onto productive and biological indicators of gosling broilers and their natural resistance.
The research tasks included studying the influence quantity of the following feed-related factors (feed additives) onto productive and biological indicators of gosling broilers: bentonite, Stimul, potassium iodide, casein iodide, sodium selenite, , Sel-Plex, Vetocel E forte, Avizyme 1200 (as a part of a wheat feed mix), Avizyme 1200 (as a part of a wheat-andbarley feed mix), Natufos, Liv 52 Vet, Levisel SB plus, Agrimos, Vetom, Lactobifadol.

\section{METHODS}

The study of influence quantity of the feeding factors (all the feed additives analyzed) was conducted on gosling broilers of Italian White breed throughout 15 experiments. Poultry raising period was 60 days in all the experiments. The raising of gosling broilers proceeded in two periods: starting (weeks 1 through 3) and finishing (weeks 4 through 9). Feeding of the goslings was based on the norms stipulated by VNITI of Poultry Raising. All the experiments were performed at the premises of OOO Makhalov Pedigree Farm, Kurgan oblast.

The goslings were weighed individually ( 50 birds from each group), once every 10 days before the morning feeding. At the end of each experiment (the end of raising), the birds were slaughtered, the carcasses of the goslings were anatomized to reveal the influence of feed additives onto goose meat productivity following the methodological guidelines prescribed by VASKhNIL and VNITIP.

Samples of blood were taken from anal vein in the middle of raising to study the hematological indicators and natural resistance indicators. The research was conducted in accordance with standard methodologies.

The living conditions of the experimental poultry were identical in all the experiments and complied with necessary process requirements. All the birds in the experiments were clinically healthy. Throughout the experimental period, the

\footnotetext{
* The research has been conducted with the financial assistance from the Russian Foundation for Basic Research within the framework of a research project 1744-450864 p_a «Experimental and computer modeling of influence from external factors onto indicators of biological systems»
} 
goslings were under observation of a veterinarian, a livestock specialist and several poultry maids.

Experimental raw data was processed with univariate and bivariate analysis of variance with the Student's t-test. The range of influence quantity of various factors over the indicators was: for live weight the value below $10 \%$ was considered a weak influence, from $10 \%$ to $20 \%$ was considered a moderate influence, over $20 \%$ it was considered a strong influence; for the rest of the indicators, below $20 \%$ was considered weak influence, from 20 to $50 \%$ was considered a moderate influence, and over 50\% was considered a strong influence.

\section{RESEARCH RESULTS}

As a result of the research, it has been established that the studied feed-related factors had ambiguous influence on productive and biological indicators of gosling broilers.

Poultry productivity is an economically-useful attribute with a high degree of variance that is determined by multiple factors including feeding. Biostimulating action of feed additives onto poultry organism is manifested in increase of its viability, growth rate and feed use efficiency [1 - 5] (Table 1).

TABLE 1 - INFLUENCE OF VARIOUS FEED-RELATED FACTORS OVER LIVE WEIGHT OF GOSLING BROILERS, \%

\begin{tabular}{|c|c|c|c|c|}
\hline \multirow[b]{2}{*}{$\begin{array}{c}\text { Factor } \\
\text { (Feed additive) }\end{array}$} & \multicolumn{4}{|c|}{ Live weight } \\
\hline & 10 days & 30 days & 60 days & $\begin{array}{c}\text { Daily } \\
\text { average } \\
\text { increment }\end{array}$ \\
\hline Bentonite & 11.88 & 9.04 & 5.22 & 5.18 \\
\hline Stimul & $15.71 *$ & $21.13 * *$ & $25.27 * *$ & $23.34 * *$ \\
\hline Potassium iodide & 9.64 & $19.80 *$ & 10.74 & 10.68 \\
\hline Casein iodide & 1.00 & 4.58 & $25.07 * *$ & $24.98 * *$ \\
\hline Sodium selenite & 1.27 & 4.46 & 3.76 & 3.74 \\
\hline Sel-Plex & 7.97 & 10.10 & 11.07 & 11.07 \\
\hline Vetosel E forte & 3.12 & 5.13 & 8.29 & 8.31 \\
\hline $\begin{array}{l}\text { Avizyme } 1200 \\
\text { (wheat } \\
\text { feed mixture) }\end{array}$ & 14.07 & $18.29 * *$ & $23.21 * *$ & $23.21 * *$ \\
\hline $\begin{array}{l}\text { Avizyme } 1200 \\
\text { (wheat-and-barley } \\
\text { feed mixture) }\end{array}$ & 11.14 & $16.32 * *$ & $19.71 * *$ & $20.02 * *$ \\
\hline Naturfos & $9.45 * *$ & $12.25 * *$ & $14.00 * *$ & $25.54 * *$ \\
\hline Liv 52 Vet & $22.20 * *$ & $18.92 * *$ & $18.29 * *$ & $18.40 * *$ \\
\hline Levisel SB plus & 1.56 & 7.70 & 7.68 & 7.03 \\
\hline Agrimos & 1.19 & 7.67 & 11.08 & 11.56 \\
\hline Vetom & $15.82 * *$ & $27.57 * *$ & $31.17 * *$ & $30.12 * *$ \\
\hline Lactobifadol & $21.64 * *$ & $24.69 * *$ & $33.54 * *$ & $32.67 * *$ \\
\hline
\end{tabular}

It has been established, that the largest influence onto live weight of gosling broilers was exerted by application of probiodic feed additives (Vetom and Lactobifadol) and Stimul feed additive. The influence onto live weight from feeding the gosling broilers with the Vetom probiotic was $15.82 \%$ at the age of 10 days at $\mathrm{P} \leq 0.01 ; 27.57 \%$ at the age of 30 days at $\mathrm{P} \leq 0.01 ; 31.17 \%$ at the age of 60 days at $\mathrm{P} \leq 0,01$; the influence onto the daily average increment was $30.12 \%$, at $\mathrm{P} \leq 0,01$; the influence of Lactobifadol onto the live weight was $21.64 \%$ at the age of 10 days at $\mathrm{P} \leq 0.01 ; 24.69 \%$ at the age of 30 days at $\mathrm{P} \leq 0.01 ; 33.54 \%$ at the age of 60 days at $\mathrm{P} \leq 0.01$; its influence over the daily average increment was $32.67 \%$ at $\mathrm{P} \leq 0.01$. The influence of the Stimul feed additive was $15.71 \%$ at the age of 10 days at $\mathrm{P} \leq 0.05 ; 21.13 \%$ at the age of 30 days at $\mathrm{P} \leq 0.01$;
$25.27 \%$ at the age of 60 days at $\mathrm{P} \leq 0,01$; its influence over the daily average increment was $23.34 \%$ at $\mathrm{P} \leq 0.01$. On average, the influence of the Stimul feed additive onto the live weight (taking into account all the indicators in this group) amounted to $21.36 \%$; the influence of the probiotic preparations was $26.17 \%$ (Vetom) and $28.14 \%$ (Lactobifadol), that is, the influence quantity of these feed additives was in the upper range.

In the moderate range as for the influence onto the live weight of gosling broilers (taking into account all the indicators in this group), there are the following additives: Liv 52 Vet phytobiotic (19,45\%); various enzymes, such as: Avizyme 1200 on a wheat feed mixture (19.70\%); Avizyme 1200 in a wheatand-barley feed mix $(16,80 \%)$ and Naturfos $(15.31 \%)$, as well as feed additives that contain iodine (potassium iodide $(12.72 \%)$ and casein iodide (13.91\%). However, analyzing the influence quantity from application of the feed additives in the context of individual indicators, it should be noted that the difference between the minimal and maximal influence quantity was less pronounced when the Liv 52 Vet phytobiotic was used: from $18.29 \%$ of influence onto the live weight of gosling broilers at 60 days to $22.20 \%$ of influence onto the live weight at the age of 10 days.

When other feed additives were used in gosling broiler feed, where the influence quantity onto the live weight was in the middle range, the difference between the maximum and minimum of influence was higher: Avizyme 1200 enzymes on wheat feed mixture $(9.14 \%)$, Avizyme 1200 in wheat-andbarley feed mixture $(8,88 \%)$, Naturfos $(16.09 \%)$; iodinecontaining additives: potassium iodide $(10.16 \%)$ and casein iodide $(24.07 \%)$.

Application of bentonite, sodium selenite, Sel-Plex, Vetosel E forte, Levisel SB plus and Agrimos as feed additives did not have a significant influence over the live weight of gosling broilers, the influence quantity was in the low range. The influence quantity of bentonite introduced into gosling broiler feed varied in a range from $5.18 \%$ (on daily average increment) to $11.88 \%$ (on live weight at the age of 10 days); that of sodium selenite - from $1.27 \%$ (on live weight at the age of 10 days) to $4.46 \%$ (on live weight at the age of 30 days); the influence quantity of Sel-Plex varied from $7.97 \%$ (on live weight at the age of 10 days) to 11.07 (on live weight at the age of 60 days). The effect from introduction of Vetosel $\mathrm{E}$ forte varied from $3.12 \%$ (on live weight at the age of 10 days) to $8.31 \%$ (on daily average increment); that from Levisel SB plus varied from $1.56 \%$ (on live weight at the age of 10 days) to $7.68 \%$ (on live weight at the age of 60 days). Introduction of Agrimos showed influence varying from $1.19 \%$ (on live weight at the age of 10 days) to $11.56 \%$ (at daily average increment)

Thus, the average influence quantity onto live weight indicators of gosling broilers was maximal for the following additives: Vetom (26.17\%), Lactobifadol (28,14\%), Stimul $(21.36 \%)$, Avizyme 1200 enzyme in wheat feed mixes $(19.70 \%)$ and Liv 52 Vet phytobiotic (19.45\%). Several additives showed almost no influence: Vetosel $\mathrm{E}$ forte (averaged indicators of live weight amounted to $6.21 \%$ ), Levisel SB plus (averaged indicators of live weight amounted 
to $5.99 \%$ ) and sodium selenite (averaged indicators of live weight amounted to $3,31 \%$ ).

Morphological and biochemical characteristics of blood hold a special place and are important for evaluation of physiological status of an organism and timely diagnostics. Blood provides connection of metabolic processes that take place in various organs and tissues, thus performing protective, transport, regulatory, respiratory, thermotaxic and other functions [6-7]. The influence quantity of feed-related factors onto the morphological and biochemical blood levels of gosling broilers is shown in Figures 1 and 2.

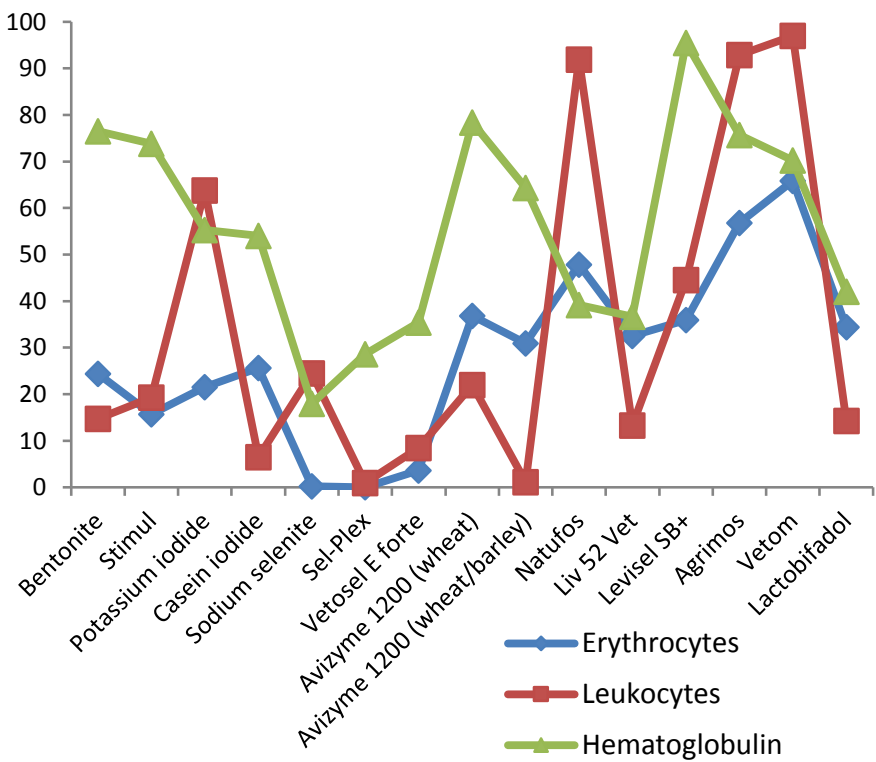

Fig. 1 - Influence of various feed-related factors over the morphological blood levels of gosling broilers, $\%$

When evaluating the influence of feed-related factors onto morphological blood levels, it was established, that five feed additives showed maximum influence (taking into account the influence of feed factors onto all the morphological levels): Probiotics Vetom (75.48\%), Levisel SB plus $(61.09 \%)$, prebiotic Agrimos (69.28\%), and enzymes Naturfos (62.59\%) and Avizyme 1200 in a wheat feed mix (50.49\%) (the influence quantity is in the high range). The difference in influence (between the maximum and the minimum) of various additives introduced in gosling broiler feed varied: for Vetom probiotic from $65.84 \%$ at $\mathrm{P} \leq 0.01$ (on erythrocyte count) to $96.98 \%$, at $\mathrm{P} \leq 0.05$ (on leukocyte count) and amounted to $31.14 \%$; for Agrimos prebiotic from 51.72\% at $\mathrm{P} \leq 0.01$ (for blood quotient) to $92.86 \%$ at $\mathrm{P} \leq 0.01$ (on leukocyte count) and amounted to $59.60 \%$; for Levicel SB plus probiotic from $35.92 \%$ at $\mathrm{P} \leq 0.01$ (on erythrocyte count) to $95.52 \%$ at $\mathrm{P} \leq 0.001$ (on hemoglobin content) and amounted to $59.60 \%$; for Natufos enzyme from $39.20 \%$ at $\mathrm{P} \leq 0.001$ (on hemoglobin content) to $91.89 \%$ at $\mathrm{P} \leq 0.05$ (on leukocyte count) and amounted to $52.69 \%$; for Avizyme 1200 enzyme in wheat feed mix from $22.01 \%$, at $\mathrm{P} \leq 0.001$ (on leukocyte count) to $78.40 \%$ at $\mathrm{P} \leq 0.01$ (on hemoglobin content) and amounted to $56.39 \%$.

When evaluating the influence of feed-related factors onto morphological blood levels, it was established, that five feed additives showed moderate influence (taking into account the influence of feed factors onto all the morphological levels): potassium iodide (41.61\%); bentonite (39.73\%); Stimul (37.59\%); Lactobifadol probiotic $(36.63 \%)$; Liv 52 Vet phytobiotic (36.53\%) and Avizyme 1200 enzyme in wheat-andbarley feed mix $(31.89 \%)$. When evaluating the influence of feed-related factors onto morphological blood levels, it was established, that the low level of influence was characteristic of selenium-containing additives (taking into account the influence of feed factors onto all the morphological levels): sodium selenite (14.75\%); Sel-Plex (11.65\%) and Vetosel E forte $(13.86 \%)$.

Such an indicator as leukocyte count cannot be included in the evaluated indicators, as the influence quantity of feed additives introduced to gosling broilers significantly deviates from mean values for all the morphological blood levels. For example, when using bentonite as a feed-related factor, while the average influence quantity was $48.07 \%$, the leukocyte count was $14.77 \%$. The same values for Stimul were 37.59 and $19.25 \%$; for potassium iodide they were 34.23 and $63.75 \%$; for casein iodide they were 29.57 and $6.46 \%$; for sodium selenite they were 11.51 and $24.45 \%$; for Sel-Plex they were 15.22 and $0.96 \%$; for Vetosel $\mathrm{E}$ forte they were 15.66 and $8.44 \%$; for Avizyme 1200 in wheat feed mix they were 59.98 and $22.01 \%$; for Avizyme 1200 in wheat-and-barley feed mix they were 31.89 and $1.10 \%$; for Natufos they were 52.82 and $91.89 \%$; for Liv 52 Vet they were 44.27 and $13.32 \%$; for Levisel SB plus they were 61.09 and $44.57 \%$; for Agrimos they were 69.28 and $92.86 \%$; for Vetom they were 68.31 and $96.98 \%$; for Lactobifadol they were -44.09 and $14.25 \%$, respectively.

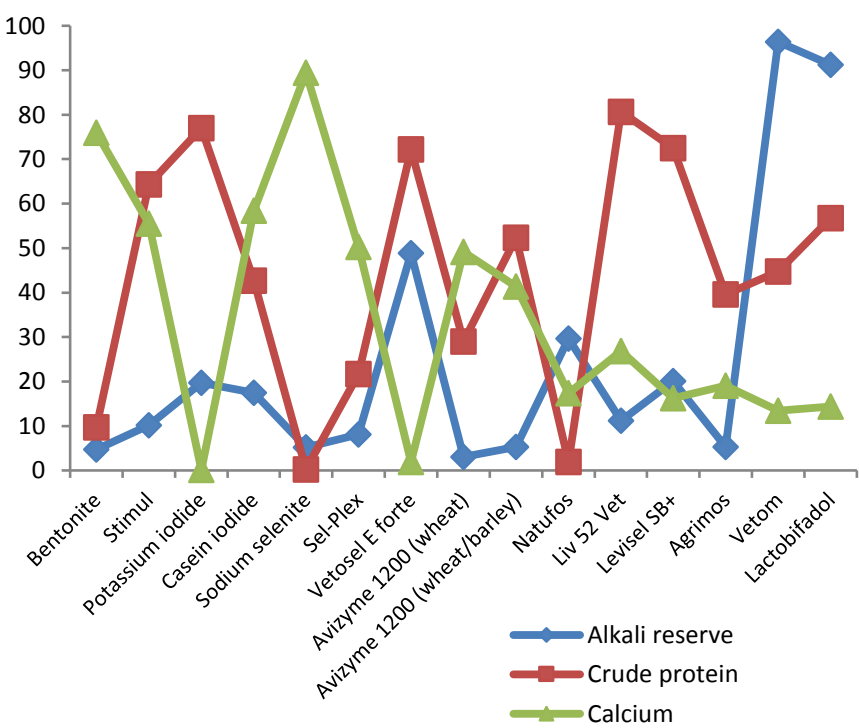

Fig. 2 - Influence of various feed-related factors over the biochemical blood levels of gosling broilers, $\%$

At that, after removing the leukocyte count from the evaluated indicators, the influence quantity level of each of the studied feed factors stayed in the same range: The high range included Vetom and Levisel SB plus probiotics, Agrimos prebiotic, Natufos and Avizyme 1200 in wheat feed mix; the moderate level included potassium iodide, Stimul, bentonite, Lactobifadol probiotic, Liv 52 Vet phytobiotic and Avizyme 1200 enzyme in wheat-and-barley feed mix; the low level included selen-containing additives; however, the difference 
between the minimum and maximum influence quantity of various feed factors onto morphological blood levels of gosling boilers was reduced significantly.

The quantity of influence that the feed factors exert over the biochemical blood levels of gosling broilers varied significantly, depending on both studied feed additives and the indicator being estimated.

For example, the alkali reserve of the gosling broilers was strongly influenced by two probiotics, Vetom $(96.39 \%$ at $\mathrm{P} \leq 0.05)$ and Lactobifadol (91.24\% at $\mathrm{P} \leq 0.05)$, respectively). The influence of Vetosel $\mathrm{E}$ forte $(48.89 \%$ at $\mathrm{P} \leq 0.001)$, the Natufos enzyme (29.62\%) and the Levisel SB plus probiotic $(20.11 \%)$ onto the alkali reserve of gosling broilers was in the moderate range. The influence of the rest of the studied feed additives was in the lower range: from 3.06\% (Avizyme 1200 in wheat feed mix) to $19.69 \%$ (potassium iodide).

A high quantity of influence over the crude protein in blood of gosling broilers was registered for potassium iodide $(77.00 \%$ at $\mathrm{P} \leq 0.01)$, Vetosel $\mathrm{E}$ forte $(72.19 \%$ at $\mathrm{P} \leq 0.01)$, the Liv 52 Vet phytobiotic $(80.67 \%$ at $\mathrm{P} \leq 0.01)$, Lactobifadol probiotic $(56.74 \%$ at $\mathrm{P} \leq 0.001)$ and the Levisel SB plus probiotic $(72.44 \%$ at $\mathrm{P} \leq 0.001)$; the Stimul feed additive $(64.29 \%$ at $\mathrm{P} \leq 0.01)$ and the Avizyme 1200 enzyme in wheat-and-barley feed mix (52.31\% at $\mathrm{P} \leq 0.001)$.

A moderate quantity of influence over the crude protein in blood of gosling broilers was registered for the Vetom probiotic $(44.77 \%$ at $\mathrm{P} \leq 0.001)$ and the Agrimos probiotic $(39.60 \%$ at $\mathrm{P} \leq 0.001)$; casein iodide feed additive $(42.64 \%$ at $\mathrm{P} \leq 0,01)$; the Avizyme 1200 enzyme in wheat feed mix $(28.96 \%$ at $\mathrm{P} \leq 0.001)$ and the Sel-Plex enzyme $(21,69 \%)$.

A low quantity of influence over the crude protein in blood of gosling broilers was registered as a result of application of such feed additives as bentonite $(9.70 \%)$; sodium selenite $(0.25 \%)$, Natufos enzyme (1,87\%).

Content of mineral components of gosling broiler blood (potassium and inorganic phosphorus) experienced an influence in the high range from the application of the following feed additives: casein iodide (58.46 and $83.64 \%$ at $\mathrm{P} \leq 0.01$, respectively); sodium selenite $(89.47$ and $81.70 \%$ at $\mathrm{P} \leq 0.01$, respectively); Sel-Plex (50.29 and $60.00 \%$ at $\mathrm{P} \leq 0.01$, respectively). Use of bentonite and Stimul in the feeding of gosling broilers also significantly influenced the calcium content of blood, with the influence quantity of $75.90 \%$ at $\mathrm{P} \leq 0.01$ and $55.53 \%$ at $\mathrm{P} \leq 0.01$, respectively. In the high range of influence over the content of inorganic phosphorus in the blood of gosling broilers, there are Levisel SB plus probiotic with 65.13 at $\mathrm{P} \leq 0.001$ and Agrimos prebiotic with 57.70 at $\mathrm{P} \leq 0.001$.

In the moderate range of influence over the calcium content in the blood of gosling broilers there are Avizyme 1200 in both wheat and wheat-and-barley feed mixes, as well as the Liv 52 Vet phytobiotic $(49.12 \% ; 41.36 \%$ at $\mathrm{P} \leq 0.01$, and $26.81 \%$, respectively). In the moderate range of influence over the content of inorganic phosphorus in the blood of gosling broilers, there are potassium iodide $(33.33 \%$ at $\mathrm{P} \leq 0.001)$; Stimul (24.97\%) and the Liv 52 Vet phytobiotic (24.13\%).
Low-level influence over the mineral components of gosling broiler blood was registered for the use of the following feed additives: Vetosel E forte, the Natufos enzyme, the Vetom and Lactobifadol probiotics.

Thus, when evaluating the influence of feed-related factors onto the morphological blood levels of gosling broilers, it was established, that the following feed additives showed maximum influence (taking into account the influence of feed factors onto all the morphological levels): The Vetom and Levisel SB plus probiotics (75.48 and $61.09 \%$, respectively); the Agrimos prebiotic $(61.09 \%)$, the Natufos enzyme $(62.59 \%)$ and the Avizyme 1200 enzyme in a wheat feed mix (50.49\%). When evaluating the influence of feed-related factors onto morphological blood levels, it was established, that the minimal level of influence was characteristic of selenium-containing additives (taking into account the influence of feed factors onto all the morphological levels): sodium selenite (14.75\%); SelPlex (11.65\%) and Vetosel E forte $(13.86 \%)$.

Using the biochemical blood levels as a group for evaluation of the quantity of influence that the feed-related factors exert onto gosling broilers is deemed impossible, as there are significant variations, linked to both feed additives used and the indicators being evaluated. Thus, it is impossible to establish any regularity in the influence quantity. In addition, such an indicator as leukocyte count cannot be included in the evaluated indicators, as the influence quantity of feed additives introduced to gosling broilers deviates significantly from mean values for all the morphological blood levels.

Currently, more and more attention is paid to keeping the poultry healthy, and it is hard to overestimate the importance of immune system within this context. Constant monitoring of normal cells of organs and tissues for pathogens is the most important function of the immune system [8 - 19] (Figure 3).

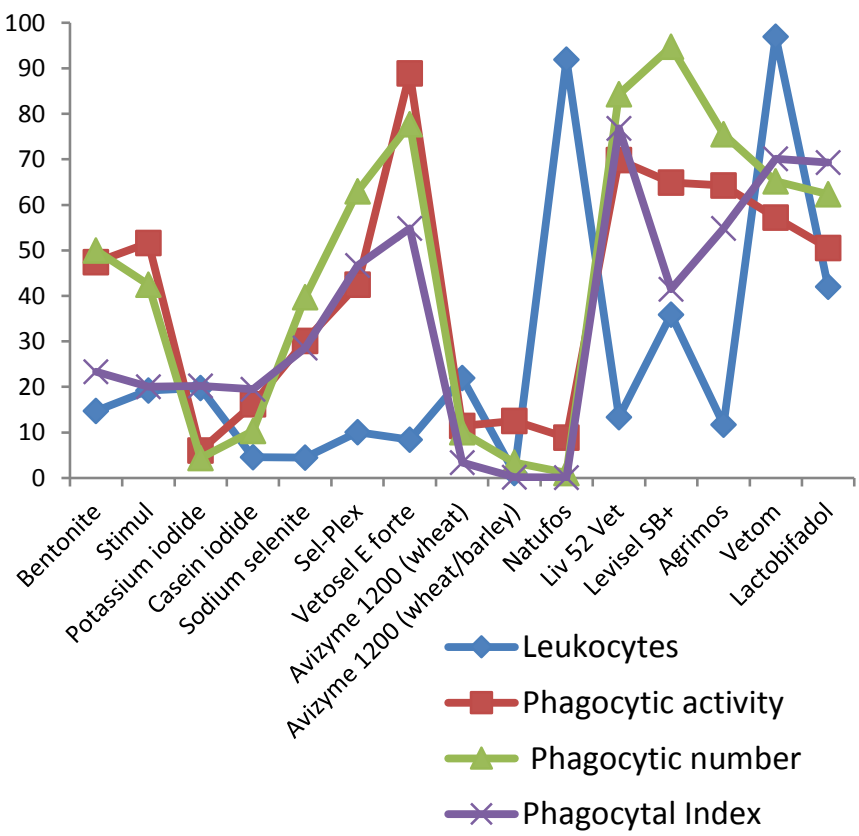

Fig. 3 - Influence of various factors over the physiological status (natural resistance) of gosling broilers, \% 
It has been established, that the natural resistance of gosling broilers was under a large influence (in the high range) of the following feed additives: Vetosel $\mathrm{E}$ forte, Levisel SB plus phytobiotic, Vetom, Lactobifadol and Levisel SB plus probiotics and Agrimos prebiotic.

The range of influence of the Vetosel $\mathrm{E}$ forte onto phagocytic activity was from $54.82 \%$ (phagocytic index) at $\mathrm{P} \leq 0.01$ to $88.90 \%$ (phagocytic activity) at $\mathrm{P} \leq 0.05$; that of Liv 52 Vet phytobiotic was from $54.92 \%$ (phagocytic capacity) at $\mathrm{P} \leq 0.001$ to $84.34 \%$ (phagocytic number) at $\mathrm{P} \leq 0.01$; that of Vetom probiotic was from $57.22 \%$ (phagocytic activity) at $\mathrm{P} \leq 0.01$ to $70.13 \%$ (phagocytic index) at $\mathrm{P} \leq 0.01$; that of Lactobifadol probiotic was from $42.03 \%$ (leukocyte count) at $\mathrm{P} \leq 0.001$ to $69.25 \%$ (phagocytic index) at $\mathrm{P} \leq 0.01$; that of Levisel SB plus probiotic was from $35.92 \%$ (leukocyte count) at $\mathrm{P} \leq 0.01$ to $94.70 \%$ (phagocytic number) at $\mathrm{P} \leq 0.01$; and that of Agrimos prebiotic was from $11.76 \%$ (leukocyte count to $91.40 \%$ (phagocytic capacity) at $\mathrm{P} \leq 0.001$. On average, the influence quantity of the feed-related factors over the phagocytic activity in gosling broilers had the following values: for Vetosel E forte $-57.95 \%$; for the Liv 52 Vet phytobiotic 59.84\%; for the Vetom, Lactobifadol and Levisel SB plus probiotics - 69.97; 56.62 and 60.99\%? Respectively; and for Agrimos prebiotic - 59,55\%.

The medium range of influence onto the fagocytic activity in gosling broilers was taken up by such feed additives as bentonite, Stimul and selenium-containing additives (sodium selenite and Sel-plex). When bentonite was used in feeding the gosling broilers, the range of their indicators of physiological status was in the range from $17.70 \%$ (leukocyte count) to $50.00 \%$, at $\mathrm{P} \leq 0.001$ (phagocytic number); for the Stimul feed additive it was in the range from $19.25 \%$ (leukocyte count) to $51.62 \%$ at $\mathrm{P} \leq 0.001$ (phagocytic activity). For sodium selenite the influence range was from $4.46 \%$ (leukocyte count) to $39.70 \%$ at $\mathrm{P} \leq 0.001$ (phagocytic number); for Sel-Plex in was from $10.10 \%$ (leukocyte count) to $62.96 \%$ (phagocytic number) at $\mathrm{P} \leq 0.01$.

On average (taking into account the influence of feedrelated factors onto natural resistance indicators), the influence quantity of the feed-related factors onto the phagocytic activity of gosling broilers amounted to: $33.54 \%$ for bentonite; $32.62 \%$ for Stimul;26.23\% for sodium selenite; $40.42 \%$ for Sel-Plex.

The quantity of influence over the physiological state of the gosling broilers from such feed-related factors as iodinecontaining additives is insignificant (low range of influence). On average, though all the indicators of influence over the natural resistance of gosling broilers, the influence quantity for potassium iodide and casein iodide were $15.50 \%$ and $11.09 \%$, respectively; for Avizyme 1200 enzyme in a wheat feed mix, Avizyme 1200 enzyme in a wheat-and-barley feed mix and Natufos enzyme the values were $13.41 \% ; 3.59 \%$ and $24.45 \%$, respectively.

Leukocyte count (just like for the morphological blood levels) may not be included with the evaluated indicators, as the influence quantity onto the leukocyte count deviates significantly from the average influence quantities showed by various feed-related factors over the natural resistance. For example, when using bentonite as a feed-related factor, while the average influence quantity was $33.54 \%$, the leukocyte count was $14.70 \%$. The same values for Stimul were 32.62 and $19.25 \%$; for potassium iodide they were 15.50 and $19.80 \%$; for casein iodide they were 11.09 and $4.58 \%$; for sodium selenite they were 26.23 and $4.46 \%$; for Sel-Plex they were 40.46 and $10.10 \%$; for Vetosel E forte they were 57.95 and $8.44 \%$; for Avizyme 1200 in wheat feed mix they were 13.41 and $22.01 \%$; for Avizyme 1200 in wheat-and-barley feed mix they were 3.59 and $1.10 \%$; for Natufos they were 24.45 and $91.89 \%$; for Liv 52 Vet they were 59.84 and $13.32 \%$; for Levisel SB plus they were 60.99 and 35.92\%; for Agrimos they were 59.55 and $11.76 \%$; for Vetom they were 69.97 and $96.98 \%$; for Lactobifadol they were -56.62 and $42.03 \%$, respectively.

Thus, maximum influence over the natural resistance of gosling broilers was exerted by application of the following factors: Vetosel E forte, Liv 52 Vet, Vetom, Levisel SB plus, Agrimos and Lactobifadol.

Meat productivity is determined by bird's capability to form a powerful muscular system at an early age. This capability is related to peculiarities of build, early meat maturation, efficiency of feed utilization. The influence of various feedrelated factors over the meat productivity of the gosling broilers is reflected in Figure 4.

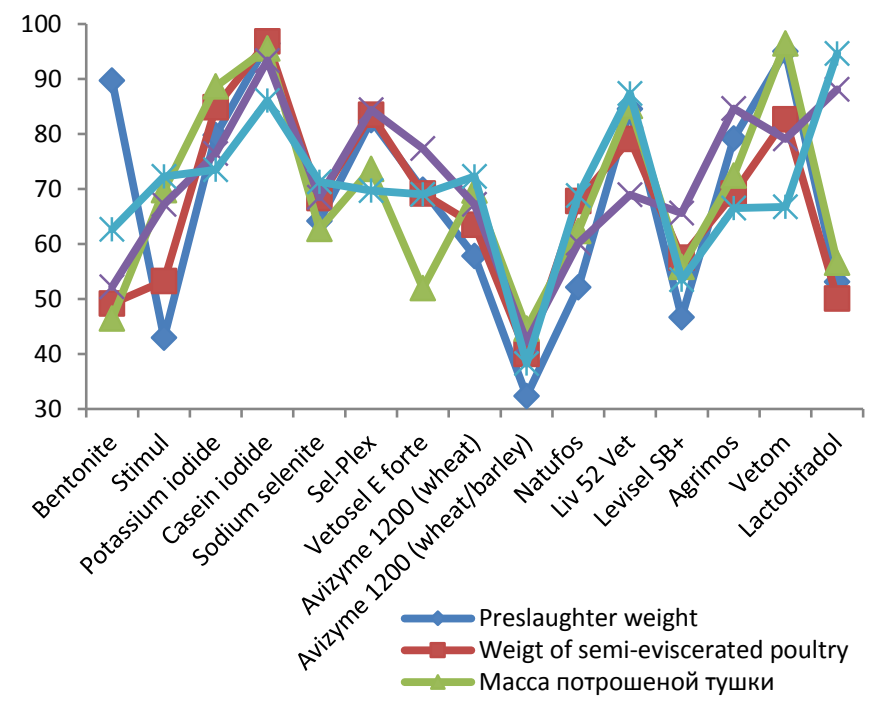

Fig. 4 - Influence of various feed-related factors over the meat productivity of gosling broilers, $\%$

It has been established, that the meat productivity of the gosling broilers was influenced by all the feed-related factors analyzed; the influence quantities (averaged over all the indicators of gosling broiler meat productivity) was in the upper range for almost all feed additives, from $58.91 \%$ for bentonite to $93.14 \%$ for casein iodide. However, the maximum influence quantity (taking into account all the indicators of meat productivity in a range from 80 to $100 \%$ ) over the meat productivity of gosling broilers was registered for the use of iodine-containing additives: $80.81 \%$ for potassium iodide and $93.14 \%$ for casein iodide; other high values were registered for Liv 52 Vet phytobiotic and Vetom probiotic at 83.51 and $80.79 \%$, respectively. Iodide-containing additives shall be highlighted among these four, as taking into account the 
minimum and maximum influence over the meat productivity they showed smaller difference: $11.38 \%$ for potassium iodide and $10.38 \%$ for casein iodide.

In the high range $(70-80 \%$ of the average quantity of influence exerted by the feed-related factors over all the meat productivity indicators of gosling broilers) there were Sel-Plex feed additive $(77.80 \%)$ with a difference between the maximum and the minimum influence quantity in $14.69 \%$ and Agrimos prebiotic $(73.35 \%)$ with the difference of $18.07 \%$. The range from 50 to $70 \%$ as averaged over all the indicators of meat productivity of the gosling broilers includes almost all the other feed additives: bentonite 58.91\%; Stimul - 62.27\%; Natufos 61.94\%; Avizyme 1200 in a wheat feed mix - 66.43\%; sodium selenite $-66.48 \%$; Vetosel E forte $-68.69 \%$ and Lactobifadol $-69.84 \%$. The moderate influence range includes only one feed additive, Avizyme 1200 enzyme in a wheat-and-barley feed mix, its influence averaged over all the indicators of the gosling broiler meat productivity was $38,42 \%$.

Thus, use of all the feed additives had significant influence over the meat productivity of gosling broilers.

\section{CONCLUSION}

The research has shown that determining the influence quantity that feed-related factors exert onto productive and biological indicators of gosling broilers helped identify the feed additives that have the maximum and minimum effect onto the studied indicators. A high degree of influence over live weight, morphological blood levels and natural resistance was registered from using the Vetom probiotic in feeding the gosling broilers. a low degree of influence over the live weight and morphological blood levels of gosling broilers was shown by selenium-containing feed additives showed, nnamely: sodium selenite, Sel-Plex and Vetosel E forte. All the feedrelated factors had strong influence onto the meat productivity of gosling broilers.

Using the biochemical blood levels as a group for evaluation of the quantity of influence that the feed-related factors exert onto gosling broilers is deemed impossible, as there are significant variations, linked to both feed additives used and the indicators being evaluated. In addition, such an indicator as leukocyte count may not be included with the morphological blood levels and natural resistance indicators, as the influence quantity of feed additives introduced to the gosling broilers deviates significantly from mean values for all the morphological blood levels.

\section{Acknowledgement}

The research has been conducted with the financial assistance from the RFFBR within the framework of a research project 17-44-450864 $p$ a «Experimental and computer modeling of influence from external factors onto indicators of biological systems»

\section{References}

[1] V.I. Fisinin, T.A. Stolyar, V.S. Buyarov, Innovative projects and technologies in meat poultry raising, "Annals of Orel State Agricultural University", 2007, no. 1. pp. $6-13$
[2] V.S. Buyarov, Ye.A. Buyarova, V.A. Borodin, "Process and economic aspects of broiler meat production", Zootechnia, 2003, no. 9. pp.24-27.

[3] A.V. Buyarov, V.S. Buyarov,. "Development priorities in meat poultry raising in Russia, "Annals of the Altai State Agricultural University", 2015, no. 6 (128), pp.165-171.

[4] Sukhanova S., Kozhevnikov S., Shulgin S. Influence of probiotic preparations onto biochemical blood indicators of gosling broilers // Glavnyi Zootechnik, 2012, no. 4, pp.55 - 57.

[5] S.F. Sukhanova, I.G. Korniyenko, "Meat productivity of geese that were fed with Levisel SB plus as a part of combination fodder", Annals of Agribusiness of Stravopol krai, 2017, no. 2 (26), pp. 105-108.

[6] G.S. Azaubayeva, "Changes in hematological indicators of gosling broilers after use of Vetom series preparation", Annals of the Kurgan State Agricultural Academy, 2017, no. 1 (21), pp. 18-21.

[7] G.S. Azaubayeva, "State of blood in animals and poultry", Kurgan: Zauralye, 2004, p. 168.

[8] I. V. Serdyuchenko, A. G. Koshchaev, N. N. Guguchvili, I. S. Zholobova I. M. Donnik, A. M. Smirnov, B. V. Usha, "Microbiocenosis of the intestinal tract of honey bees and its correction", OnLine Journal of Biological Sciences, 2018, vol. 18(1), pp. 74-83.

[9] V.I. Shcherbatov, L.I. Sidorenko, A.G. Koshchaev, V.K. Vorokov, L.N. Skvortsova, "Chicken hatching synchronization for artificial incubation " Journal of Pharmaceutical Sciences and Research, 2018, vol. 10 (1)., pp. 148-151.

[10] A.G. Koshchaev, et al, "Screening of microorganism symbiont strains as a base of probiotics for poultry industry", Journal of Pharmaceutical Sciences and Research, 2017, vol. 9 (8)., pp. 1373-1379.

[11] M.A. Chasovshchikova , O.M. Sheveleva , M.A. Svjazhenina., N.I Tatarkina , A.B. Satkeeva, A.A. Bakharev , E.A. Ponomareva, A.G. Koshchaev, "Relationship between the genetic variants of kappa-casein and prolactin and the productive-biological characteristics of cows of the black-motley breed", Journal of Pharmaceutical Sciences and Research, 2017, vol. 9 (7), pp. 1038-1044.

[12] I.V. Sobol, L.V. Donchenko, L.Y. Rodionova, A.G. Koshchaev, A.V. Stepovoy, "Peculiarities of analytical characteristics of pectins extracted from sunflower hearts", Asian Journal of Pharmaceutics, 2017, no. 11(1), pp. S97-S100.

[13] A.G. Koshchaev, I.V.Shchukina, M.P. Semenenko, K.V. Vasilevich et al, "Amino acid profile of meat of specialized beef breeds", Research Journal of Pharmaceutical, Biological and Chemical Sciences, 2016, no.7 (5), pp. 670-676.

[14] G.A. Plutakhin, A.G. Koshchaev, I.M. Donnik, "Quality assessment of chicken meat by analysis-of-variance method", Research Journal of Pharmaceutical, Biological and Chemical Sciences, 2016, no.7 (3), pp. 2293-2299.

[15] V.V Radchenko., E.V Ilnitskaya., A.S. Rodionova., T.M. Shuvaeva., Y.A. Lysenko, G.A. Plutakhin, A.I. Manolov, I.M Donnik, A.G.Koshchaev, "Identification of autochthonous strains as a basis for the development of the therapeutic and profylactic probiotics", Russian Journal of Biopharmaceuticals, 2016, no. 8(1), pp. 3-12.

[16] A.V. Garkovenko, V.V. Radchenko, E. V. Ilnitskaya, A. G. Koshchaev. I.V. Shchukina., A.A. Bakharev., S. F. Sukhanova, "Polymorphism of cattle microsatellite complexes", Journal of Pharmaceutical Sciences and Research, 2018, no. 10 (6), pp. 1545-1551.

[17] O.U. Chernykh, A.G. Koshchaev, A.A.Lysenko, A.A. Shevchenko., A. V Mishchenko, "Experience of diagnostics and containment of foot and mouth disease of cattle in Krasnodar region, Russia", Journal of Experimental Biology and Agricultural Sciences, 2017, no. 5, pp. 786792

[18] A.A. Nesterenko, A. G. Koshchaev., N. V. Kenijz, D. S. Shhalahov, K. R. Vilts,'Development of device for electromagnetic treatment of raw meat and starter cultures", Research Journal of Pharmaceutical Biological and Chemical Sciences, 2017, no. 8, pp. 1080-1085.

[19] A. A. Nesterenko., A. G. Koshchaev, N. V. Kenijz, D. S. Shhalahov, K Vilts, "Effect of low frequency electromagnetic treatment on raw meat", Research Journal of Pharmaceutical Biological and Chemical Sciences, 2017, no. 8, pp. 1071-10 